\title{
Nutrition knowledge of Irish Dancers
}

\author{
J. Challis ${ }^{1}$, R. Cahalan ${ }^{2}$, L. Cronin ${ }^{1}$, S. Reeves ${ }^{1}$ and O. NiBhriain ${ }^{2}$ \\ ${ }^{1}$ University of Roehampton, London, SW15 4JD and \\ ${ }^{2}$ University of Limerick, Sreelane, Castletroy, Co. Limerick, Ireland
}

It has long been known that the effect of nutrition intake on sports performance is significant ${ }^{(1,2)}$. There is a lack of information on the effect of nutrition specifically on dance performance but as dance has been described as a high intensity intermittent exercise ${ }^{(3)}$ it is similar to that of a multi-sprint team sport ${ }^{(4)}$. There is evidence that dancers do not consume an adequate intake of some nutrients ${ }^{(5)}$. Before dietary behaviour can change in athletes and dancers, knowledge of desired behaviour is required ${ }^{(6)}$. While there is some information available as to the nutrition knowledge of dancers, ${ }^{(7)}$ there is none as yet on Irish Dancers. This study looks at initial questionnaires from a longitudinal study on nutrition knowledge and intakes in Irish Dancers.

32 Irish dancers (30 female, 2 male, mean age 21.5 years, SD2.7) either in full time vocational training or professional dancers were recruited in Limerick. All participants were screened with EAT-26 and completed a validated sports nutrition knowledge questionnaire ${ }^{(8)}$ modified only for local foods/drinks. Ethical approval was granted through the procedures of the University of Roehampton and the University of Limerick.

Mean score for the questionnaire was 30.3/65, SD7.9 (47\%, SD12\%), range 9-44 (14-68\%). This compared with $85 \%$ scored by nutrition students, $45 \%$ scored by business students and $59 \%$ scored by fitness students in the validation of the original questionnaire. The ability of the Irish dancers to correctly identify foods as being high or low in carbohydrate, protein and fat varied widely. Mean (SD) score for correctly identifying foods high or low in carbohydrate was $4.1(1.4)$ out of 6 , for foods high or low in protein $4.7(1.6)$ out of 6 , for foods high or low in fat $2.8(1.4)$ out of 7.11 participants $(34 \%)$ identified pasta as a high fat food, while $10(31 \%)$ participants identified butter as a high carbohydrate food. Although $11(34 \%)$ believed that salt tablets should be used to treat cramp in dancers, $30(94 \%)$ were able to correctly identify suitable drinks for after a training session.

Nutrition knowledge amongst Irish dancers is variable, and knowledge of macronutrient content is not consistent. Without knowledge of macronutrient content of foods making choices based on recommendations to support dance training and performance will be difficult. These findings highlight the importance of providing accurate information to this group to allow them to make the best choices of food to support dance training and performance.

1. Bergström J, Hultman E (1972) JAMA 221(9): 999-1006.

2. Tarnopolsky M (2004) Nutrition 20(7): 662-8.

3. Wyon M, Koutedakis Y (2013) J Dance Med Sci 17(2): 63-69.

4. Reilly T (1997) J Sports Sci 15, 257-263.

5. Beck K, Mitchell S, Foskett A, Conlon C, von Hurst P (2015) Int J Sport Nutr \& Exerc Metab 25(4): $335-343$.

6. Birkenhead K, Slater G (2015) Sports Med 45(11): 1511-1522.

7. Wyon M, Hutchings K, Wells A, Nevill A (2014) Clin J Sport Med 24(5): 390-396.

8. Zinn C, Schofield G, Wall C (2005) J Sci Med Sport 8(3): 346-351. 